\title{
Motion analysis systems as optimization training tools in combat sports and martial arts
}

\author{
Ewa POLAK ${ }^{*}$, Jerzy KULASA ${ }^{1}$, António VENCESBRITO², Maria António CASTRO ${ }^{3}$, \& Orlando \\ FERNANDES 4 \\ ${ }^{1}$ Faculty of Physical Education, University of Rzeszow, Rzeszow (Poland) \\ ${ }^{2}$ Sport Sciences School of Rio Maior, Polytechnic Institute of Santarém, Rio Maior (Portugal) \\ 3 Physiotherapy Department of Coimbra Health School - Polytechnic Institute of Coimbra, and \\ Mechanical Engineering Research Center - University of Coimbra, Coimbra (Portugal) \\ ${ }^{4}$ Department of Sport and Health, University ofÉvora, Évora (Portugal)
}

Recepción: 18/04/2015; Aceptación: 14/12/2015; Publicación: 08/01/2016.

\begin{abstract}
Introduction: Over the past years, a few review papers about possibilities of using motion analysis systems in sport were published, but there are no articles that discuss this problem in the field of combat sports and martial arts.

Aim: This study presents the diversity of contemporary motion analysis systems both, those that are used in scientific research, as well as those that can be applied in daily work of coaches and athletes in combat sports and martial arts. An additional aim is the indication of example applications in scientific research and range of applications in optimizing the training process.

It presents a brief description of each type of systems that are currently used in sport, specific examples of systems and the main advantages and disadvantages of using them. The presentation and discussion takes place in the following sections: motion analysis utility for combat sports and martial arts, systems using digital video and systems using markers, sensors or transmitters.

Conclusions: Not all types of motion analysis systems used in sport are suitable for combat sports and martial arts. Scientific studies conducted so far showed the usefulness of video-based, optical and electromechanical systems. The use of research results made with complex motion analysis systems, or made with simple systems, local application and immediate visualization is important for the preparation of training and its optimization. It may lead to technical and tactical improvement in athletes as well as the prevention of injuries in combat sports and martial arts.
\end{abstract}

ORIGINAL PAPER

Keywords: Sports training; motion capture; information technology; combat sports; martial arts.

\begin{abstract}
Los sistemas de análisis del movimiento como herramientas para optimizar el entrenamiento en deportes de combate $y$ artes marciales

\section{Resumen}

Introducción: Durante los últimos años se han publicado algunos trabajos de revisión sobre las posibilidades que ofrece la utilización de los sistemas de análisis del movimiento en el deporte. Sin embargo, aún no existen trabajos específicos sobre deportes de combate y artes marciales.

Objetivo: Este estudio presenta los diversos sistemas contemporáneos de análisis de movimiento, tanto los utilizados en la investigación científica como aquellos que pueden utilizar cotidianamente los entrenadores y atletas de deportes de combate y artes marciales. Un objetivo adicional es ofrecer ejemplos de aplicaciones en la investigación científica así diversas aplicaciones para la optimización del proceso de entrenamiento.

Se presenta una breve descripción de cada tipo de sistema utilizado actualmente en el deporte, ejemplos específicos
\end{abstract}

\section{Sistemas de análise do movimento como} instrumentos para otimizar o treino em esportes de combate e artes marciais

\section{Resumo}

Introdução: Ao longo dos últimos anos alguns trabalhos de revisão sobre as possibilidades de utilização de sistemas de análise do movimento no desporto foram publicados, todavia no âmbito especifico da prática dos desportos de combate e artes marciais artes mas não há trabalhos de revisão publicados sobre esta temática.

Objectivo: Este estudo apresenta a diversidade dos sistemas contemporâneos de análise de movimento que são usados na investigação científica, assim como aqueles que podem ser utilizados nos desportos de combate e artes marciais por treinadores e atletas para analise e controlo do seu trabalho diário. Um segundo objectivo é a indicação de aplicações exemplos relativas à investigação científica e a gama de aplicações para optimizar o processo de treino.

É apresentada uma breve descrição de cada tipo de

\footnotetext{
${ }^{*}$ E-mail: ewpol@op.pl. Address: Faculty of Physical Education, University of Rzeszow. 35-959 Rzeszow, ul. Towarnickiego 3 (Poland).
} 
de sistemas y las principales ventajas y desventajas derivadas de su uso. La presentación y discusión se desarrollan en las siguientes secciones: utilidad del análisis del movimiento en deportes de combate y artes marciales, sistemas que utilizan el vídeo digital y sistemas que utilizan marcadores, sensores o transmisores.

Conclusiones: No todos los tipos de sistemas de análisis de movimiento utilizados en el deporte son adecuados para deportes de combate y artes marciales. Los estudios científicos realizados hasta ahora han mostrado la utilidad de los sistemas basados en vídeo, ópticos y electromecánicos. La utilización por los entrenadores y atletas de los resultados de investigaciones realizadas con sistemas de análisis de movimiento complejos, o realizados con sistemas simples, de aplicación local y visualización inmediata, es importante para preparar y optimizar el entrenamiento. Todo ello puede conducir a la mejora técnica y táctica de los deportistas, así como a la prevención de lesiones en los deportes de combate y las artes marciales.

Palabras clave: Entrenamiento deportivo; análisis del movimiento, tecnologia de la información, deportes de combate; artes marciales. sistema que é actualmente usado no desporto, com exemplos específicos e com a indicação das suas principais vantagens e desvantagens relativamente ao seu uso. A exposição e discussão é realizada nas seguintes secções: a utilidade da análise de movimento para os desportos de combate e artes marciais, os sistemas que usam vídeo digital e os sistemas que utilizam marcadores, sensores ou transmissores.

Conclusões: Nem todos os tipos de sistemas de análise de movimento são adequados para desportos de combate e artes marciais. Estudos científicos realizados até agora incidem na utilização de sistemas ópticos baseados em vídeo e sistemas electromecânicos. A utilização por treinadores e atletas dos resultados da investigação feita com sistemas de análise do movimento complexos, ou feita com sistemas simples, de aplicação local e imediata é importante para a preparação do treino e a sua optimização, podendo conduzir à melhoria técnica e táctica do atleta, bem como à prevenção de lesões nos desportos de combate e artes marciais.

Palavras-chave: Treino desportivo; análise do movimento; tecnologia da informação; desportos de combate; artes marciais.

\section{Introduction}

Many areas of modern life use motion analysis systems. Various analyses based on capturing of human motion are now one of the most active research topics. The growing need causes the necessity to make more and more technologically advanced motion capture techniques. A lot of different scientists such as Gavrila (1999), Aggarwal and Cai (1999), Wang, Hu and Tan (2003), King and Paulson (2007) wrote about changes and projected directions of their development. Extremely interesting are works written by Moeslund and Granum (2001) and Moeslund, Hilton and Krüger (2006). In these works the newest trends in vision-based human motion capture and analysis are shown. What is more, they also point on the directions of development in order to gain the possibility of automatic visual analysis. This large interest is driven by wide spectrum of applications in many fields such as: film and video games industries, medicine, sport, virtual reality, intelligent surveillance etc. However, each of these areas has its own specific assignments. In games and film productions the usage of such systems concentrates on precise registering of human movement which is used to create real movement of the animated characters. In medicine it is used mainly in diagnosis of the musculoskeletal system and monitoring of rehabilitation effects. The requirements for motion analysis systems in sport are totally different.

In the wide range of sport applications (scientific research, skills analyse, athletic performance, assessment of physical condition, mechanisms of injuries and their prevention or rehabilitation) motion analysis systems are an important field of interest for athletes, coaches and scientists. Nowadays such systems are used as tools for scientific research or for coaching in many sports. They are used in both individual and team sports (e.g. tennis, golf, swimming, gymnastics, archery, baseball, basketball, volleyball, soccer, rugby and others as combat sports and martial arts). They are also used for analysing various sport activities as they occur under laboratory conditions (Van der Zijden, et al., 2012; VencesBrito, 2012; VencesBrito, et al., 2014) on sport halls (Kautzner \& Junior, 2012), on playing fields (Roberts, Trewartha, \& Stokes, 2006), or even underwater (Magalhaes, et al., 2013).

Over the past years, a few review papers about possibilities of using motion analysis systems in sport were published (Liebermann, et al., 2002; Roberts, Trewartha, \& Stokes, 2006; Barris \& Button, 2008; Wilson, 2008). Among them, there are no articles that discuss specifically this problem in combat sports and martial arts.

The aim of this study is to present the diversity of contemporary motion analysis systems both, those that are used in scientific research, as well as those that can be applied in daily work of coaches and athletes in combat sports and martial arts, including specific examples of systems and 
the main advantages and disadvantages of using them. An additional aim is the indication of example applications in scientific research and range of applications in optimizing the training process. This information can help coaches or athletes who are not experts in the field of biomechanics and are interested in motion analysis.

\section{Method}

Literature searches were conducted in the most important in sport bibliographic databases (Scopus, Web of Science, PubMed, Science Direct, EBSCO) and in the scientific social network Research Gate. Key words for the search included: motion analysis, motion capture, biomechanics, martial arts and combat sports. Based on gathered literature, a review of systems for motion analysis that are used in sport through the last 10 years was carried out. The main topics of researches using these systems in combat sports and martial arts were illustrated with the examples of recommended articles. In order to present a current range of applications in scientific research the exemplary articles published since 2005 were selected.

A full review of scientific publications taking into account the results of research conducted with using motion analysis systems in combat sports and martial arts should be the subject of a separate study.

The study discusses the following sections: (1) the utility of motion analysis for combat sports and martial arts; (2) systems using digital video, and (3) systems using markers, sensors or transmitters.

\section{Results and discussion}

\subsection{The utility of motion analysis for combat sports and martial arts}

Combat sports and martial arts rely on special activities that require complex skills and tactical excellence. Typical movements performed by the athletes consist of specific stances and dynamic activities (strikes, punches, kicks, throws, blocks, falls etc.) that are performed individually or in contact with the opponent. These movements are made on the floor or aerial trajectory, in standing, kneeling or lying positions, with or without weapons. Almost all of them are characterized by high dynamics, high intensity and very short duration, usually designated as ballistic movements (VencesBrito, Rodrigues Ferreira, Cortes, Fernandes, \& Pezarat-Correia, 2011).

The proper performance in these specific activities are determined by powerful actions that can be applied in unpredictable context (Silva, Del Vecchio, Picanço, Takito, \& Franchini, 2011).

The main goal of training process in combat sports and martial arts is to achieve perfection in performance of specific techniques and tactical behaviours as well as the improvement of physical condition to the level that allows for competing with other athletes without the risk of injury. An important element of the training is the analysis of movements performed by the athletes during training sessions and competitions. Motion analysis of the activities carried out individually by the athlete in training or competition provides information about the correctness of the individual techniques, the effectiveness of athlete behaviours as so the combat structure (both temporal as well as spatial) and the identification of errors. Proper use of this information should serve for both the coaches and the athletes, how to correct errors and improve the organization of training tasks. Certainly, thanks to such information they will be able to improve the effectiveness of movements and achieve the expected progress. Additionally, they can reduce the risk of injury during training or competitions.

Just as in other sports, movements of the athlete in combat sports and martial arts can be analysed on the basis of two types of variables defining qualitative or quantitative features of motion. Visually discernible parameters are treated as qualitative features of motion. These variables include time, accuracy, rhythm, smoothness, etc. To fully evaluate the accuracy of the motion technique is also necessary determine the quantitative features of motion, expressed by means of measurable mechanical parameters. These are the performance criteria determining 
kinematic structures (concerning trajectory, velocity, acceleration, linear or angular displacement) and dynamic (concerning the forces causing motion or resulting from motion: force, torque, states of kinetic and potential energy) (Król \& Mynarski, 2005).

Information obtained from the motion analysis can be applied for different purposes, but the main goals are improving the technical execution of techniques characteristic for each type of combat sports and martial arts, such as improving the efficiency and effectiveness of training. The specific objectives of the use of motion analysis systems, important for coaches and athletes are:

- gaining a detailed knowledge of qualitative characteristics of movement,

- monitoring the time of combat structure,

- monitoring the correctness of the individual techniques,

- identifying errors in execution,

- determining the risk and the causes of injuries.

- visual feedback.

Proper use of the information obtained by using motion analysis system allows for optimizing the training effect.

These objectives can be achieved if the coaches or athletes can perform motion analysis by themselves, but they can also benefit from the information produced by researchers of motion analysis in the field of sport, as in other fields. This information, combined with the professional knowledge of biomechanics can be applied in daily training process. If coaches or athletes will be interested in results of scientific studies, they can take advantage of them during training and competition.

The most accessible way to gather the information necessary for motion analysis is to use the sense of sight. This method is most often used by coaches and athletes also in combat sports and martial arts. The eyesight may inform about the spatial positioning of the athlete's body or the sport equipment in regard to the adopted one or more reference systems. It may also inform about the time of motion execution, its rhythm and frequency. Paying attention to the changes in body position the approximate information about the speed and acceleration might be gained. The impact of athlete can also be assessed by observing the deformation of sport accessories or equipment (Erdmann, 2003). But in combat sports and martial arts anyone who observes the activities performed during training or competition can catch only a few critical moments of the ballistic movements typical of this sports (e.g. starting or ending position).

In order to trace the details of the movement, the changes that occur in the arrangement of specific body parts, to use the sense of sight is not enough. Also, if you want to know the relevant variables, characterizing the observed movement, such as the distance of displacement, velocity or duration, using only the sense of sight is not sufficient.

The specific movement performed by the athlete can be analysed only if it can be repeatedly viewed from different perspectives and with different speeds. In some cases, the athlete's body (whole or its part) is invisible for viewer because it is occluded by an opponent. Given the need to capture movements performed in the complex planes (linear and angular motion) with extreme speed it becomes necessary to use special technological solutions that are commonly known as the motion analysis systems.

\subsection{Systems using digital video}

The most popular way of motion capture is to record it with the use of a camcorder. This method is the most available. Nevertheless, its usage in motion analysis causes a lot of problems (Jabłoński, Klempous, \& Majchrzak, 2005). The analysis of the technique of motion which is registered on a video film (called cinematography analysis or videography) might be a qualitative as well as quantitative process. The qualitative analysis can be made only based on the observation of recorded videos. Such assessment has subjective character and does not require a specific and motionless position of the camcorder nor any other equipment. 
The quantitative analysis concerns gaining kinematic information from the recorded videos. In order to perform such analysis the video should be recorded by camcorder, that is set motionless, e.g. placed on a tripod. Furthermore, to register and display pictures a computer with appropriate software is necessary (Grimshaw, Lees, Fowlers, \& Burden, 2010).

The number of used camcorders depends on the number of planes in which the analysis will be performed. For the two-dimensional (2D) analysis the image registered by one camera is sufficient, but it should be placed perpendicular to the plane of motion (Figure 1). When the analysis is to concern the motion in more than one plane (three-dimensional analysis 3D) it is necessary to use at least two cameras synchronised with each other ${ }^{1}$. They should be placed in such a way that their optical axes intersect at an angle of $90^{\circ}$ (Figure 1), but acceptable range of angles is from $60^{\circ}$ to $120^{\circ}$ (Grimshaw, et al., 2010). In both cases (2D and 3D) a digital form of the video data allows to make the analysis using a special software.

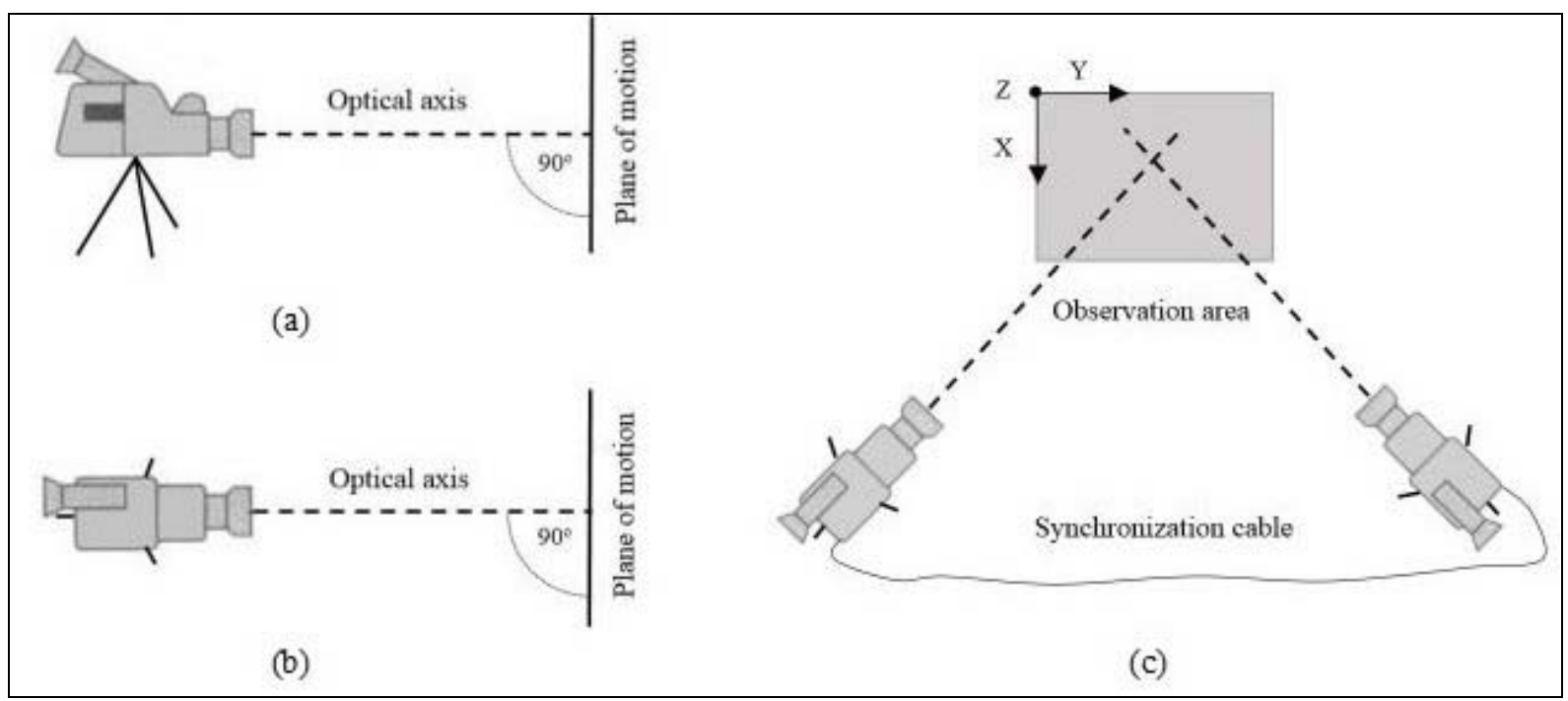

Figure 1. The setting of camcorder when recording motion for $2 \mathrm{D}$ analysis in which the optical axis of the camcorder is perpendicular to the plane of motion side (a), top (b) view, and setting of two camcorders when recording motion for 3D video analysis (c).

Nowadays, modern digital camcorders are commonly available. The technological progress causes that the camcorders are becoming smaller, more precise, with a lower price becoming easy to anyone who want to create a digital film. However, in order to obtain the relevant data from a video, a few rules that minimize errors in the measurements, need to be kept in mind. The most crucial of them are:

- motionless setting of camcorder (it is unacceptable to change the focal length, that is zoom),

- respectively large distance to the subject, providing an image of the whole motion (camera lens needs to have a small view angle, that is a big focal length, in order to reduce the change of perspective and to eliminate so called parallax error ${ }^{2}$ ),

- matching the frequency of recording to the specificity of motion, depending on the speed of movement of the subject (when the movement is faster the frequency of recording should be higher),

- placing the calibration object (flat in 2D and spatial in 3D) in the image area (Grimshaw, et al., 2010).

\footnotetext{
${ }^{1}$ Synchronization means recording the same images at the same time and with the same frequency. The easiest way to synchronize two video cameras is to use the identical cameras, connected together by special synchronization cable, which causes that camera snapshots are opened at the same time.

2 Parallax error - deformation of the object which is filmed related to its move away from the axis of the camera lens.
} 
The sequence of motion recorded as digital video images must be transferred as a file of data directly to a computer. Data transmission is usually done via USB, FireWire or eSata cables. Using the commonly available software packages designed for manipulating video files allow for a basic 2D analysis. Usually, such software allows for a slow motion replay, freeze frames, highlighting of key frames in strobe motion, overlaying video images or simple time analysis. It allows also to use multiple screen for easy comparison of synchronised images from different views, or images of different performers (Wilson, 2008).

The spatial motion analysis based on video is also possible. However, it requires obtaining huge amounts of data that need to be properly process and interpreted. Popular applications available in commonly used operating systems do not provide such possibilities. Therefore, it is important that an integral part of such systems should be special software, which allows processing and calculating relevant variables, gathered from recorded motion. To be able to perform quantitative analysis of the recorded motion, specific points of the human body should be marked on computer screen. Such specific points are the distal ends of the extremities or the joints that form the axis of rotation for particular body elements. Marking can be made manually, semi automatically or automatically depending on kind of software. Unfortunately, it often happens that the marking is not precise. To improve the precision it can be used the handmade external markers (e.g. a sticker in a contrasting colour affixed to clothes or directly to a skin). They only must be clearly visible on recorded video.

Video recording does not give the possibility of obtaining any variables for quantitative analysis in real time. Only special software packages allow to calculate the kinematics variables. Using them, it is possible to obtain the values of variables useful for linear analysis (position, trajectory, velocity, acceleration of specific body points and center of mass trajectory) and for angular analysis (joint angle, body segment angle and body angular velocity). By applying special software, with appropriate algorithms, it is also possible to obtain the kinetic variables, such as momentum, kinetic and potential energy for linear analysis or momentum and body moment of inertia for angular analysis. However, it should be noted, that such values of variables can be imprecise and can be burdened with a considerable errors.

In sport, the most often used software packages for videographic analysis are: Dartfish (http://www.dartfish.com), Kinovea (http://www.kinovea.org), SkillSpector (http://video4coach.com), SiliconCoach (http://www.siliconcoach.com), Quintic (http://www.quintic.com), Simi Motion 2D or 3D (http://www.simi.com) and FRAMI (Miarka, Hayashida, Julio, Calmet, \& Franchini, 2011). These days a lot of software packages for video motion analysis with the wide range of functions are available. The examples of free of charge solutions are: Kinovea, SiliconCoach or SkillSpector.

The advantage of video-based systems is the fact that they are portable and affordable and can be used anywhere. Additionally they may cooperate with commonly available camcorders. Such systems can process motion parameters obtained directly from video footage without using special markers. Another advantage is that such systems allow capturing the movements performed by two or more athletes who fight to each other. It can be useful for temporal and qualitative analysis in contact combat sports, such as judo and wrestling. Disadvantages are small space of recorded motion, limited by camera's field of view as well as not always precise values of variables caused by errors during video recording or incorrect marking of the specific body points on a video image.

Systems based on video technology are often used in combat sports and martial arts for scientific purposes. One of the research topics is the analysis of time structure of sports activities performed during the competition. Such analysis was performed in muai thai (Del Vecchio, Silva, \& Farias, 2015), muai thai and kick-boxing (Silva, et al., 2011), judo (Miarka, et al., 2011), karate (Kautzner \& Junior, 2012) or taekwondo (Falco, Landeo, Menescardi, Bermejo, \& Estevan, 2012; Ferreira Santos, et al., 2014). To obtain the relevant variables Kinovea, FRAMI and Nero Show Time software were used. Other scientific topics are spatiotemporal characteristics of various techniques, such as: capoeira kick (Kalichová, Vít, Reguli, \& Pieter, 2012), karate punches and kicks (Gianino, 2010; Zvonar, Kolarova, Zahradnicek, Reguli, \& Vít, 2012; Balsalobre-Fernández, Martinez-Majolero, Villacieros-Rodriguez, \& Tejero-González, 2013), taekwondo turning kick 
(Harun \& Xiong, 2010) and judo throw (Imamura, Iteya, Hreljac, \& Escamilla, 2007; Hassmann, Buchegger, \& Stollberg, 2011). For these studies basic video analysis or systems such as Dartfish, SiliconCoach, Simi Motion or Kinovea were used. The motion analysis become to be used in combat sports and martial arts also to determine the risk and the causes of injuries e.g. in mixed martial arts (Kochhar, Back, Mann, \& Skinner, 2005).

In coaches' daily work, video-based system can be the useful training tool, allowing for qualitative and quantitative comparisons and for quickly visualize the specific athlete's movement. It allows to gain precise information about the spatiotemporal parameters of motions performed by the athlete during the competition or training sessions. Such systems allow, for example, comparing the velocity of movement of the lower limb in a particular kick, between the athletes of different age. It allows for tracking changes that occur during kicking movement in terms of joint angles, such as knee or hip joint. It also lets for the registration and the synchronization different views (e.g. front, side and back) or for capturing the movements, about existence which, coaches and athletes are not aware of. Such information allows to identify errors in the execution of movements in a specific technique e.g. taekwondo side kick, during which the trainer can discuss the details trajectory of foot or any errors in positioning of the athlete's body, that can caused the lack of balance. It also allows identifying if the particular body parts are near the extremes of their range of movements, what can cause injuries. The example can be analysis of spatial positioning the upper limb that block the opponent punch in kick-boxing. Inclusion of this information in subsequent stages of training allows the athlete to correct or eliminate errors resulting of improving the efficiency and effectiveness of training process.

Such systems are not capable of observing captured movement in real time but they can be used for visual feedback. The special software packages allow that registered movement can be observed on computer screen as video images or animated images, where the athlete can be seen as animated figure (e.g. in stick figure mode). All images can be repeatedly view from different perspectives, with various speeds and with possibility of using freeze frames at any time. Special software packages allow using memo pad, zoom, lines, angles and other alignment guides to analyse patterns and differences in performed movement. For an athlete, such visual feedback allows to see how much correction it has been achieved and is useful in better understanding of what is trying to be conveyed by the coach.

Summarizing, if the coach or athlete need to analyse the qualitative variables of athlete's movement or they needs to compare them - the video-based motion analysis system are the best. These systems are also useful for visual feedback. Additionally, such systems are the only ones that can be used for temporal as well as qualitative analysis of combat structure during competitions. Video-based systems allow to obtain the variables that can inform about qualitative characteristics of movement, such as time combat structure (e.g. balance between attack and defence techniques in individual fights during the kick-boxing, taekwondo or judo competition) or accuracy and smoothness of movement performed by the full body or its part (e.g. the particular upper limb during karate punching technique). The important advantage of these systems is that they are the cheapest solution.

\subsection{Systems using markers, sensors or transmitters}

Through the rapid growth of technology the solutions to capture and analyse human movement still are developing and improving. A lot of these solutions are based on use of various types of markers, sensors or transmitters. Based on them, the following types of systems can be specified: optical, electromechanical, electromagnetic, acoustic, inertial and depth-sensing.

Optical systems are the most frequently used in sport motion analysis. These types of systems need a special area and equipment for tracking optical markers and for defining the location of human body. They usually consist of infrared cameras, infrared strobes, active or passive markers, three axes frame or wand with markers for calibration, commercial software and model defined by operator. The most significant are digital high frame rate cameras with optical filter and markers attached to specific points of subject's body. Systems of that type might be based on active optical markers (e.g. emitting the light of diode) or passive optical markers (i.e. reflecting 
the radiation). Radiation reflected or emitted by markers is synchronically registered by few cameras connected with the computer.

The number of cameras is dependent on the type of system, the manufacturer's preferences or the individual needs of users. Usually, from 6 to 8 cameras are used. Before each use the system of cameras must be calibrated (Drużbicki, Szymczyk, Snela, Dudek, \& Chuchla, 2009). For calculate 3D position of markers every single marker must be recorded by two or more cameras. Each camera can identify the direction between optical centre of camera and the place, where markers reflects the infrared on the sensor. Places, where the individual markers should be placed on the human body, depend on the defined model that is used for analysis (Figure 2).

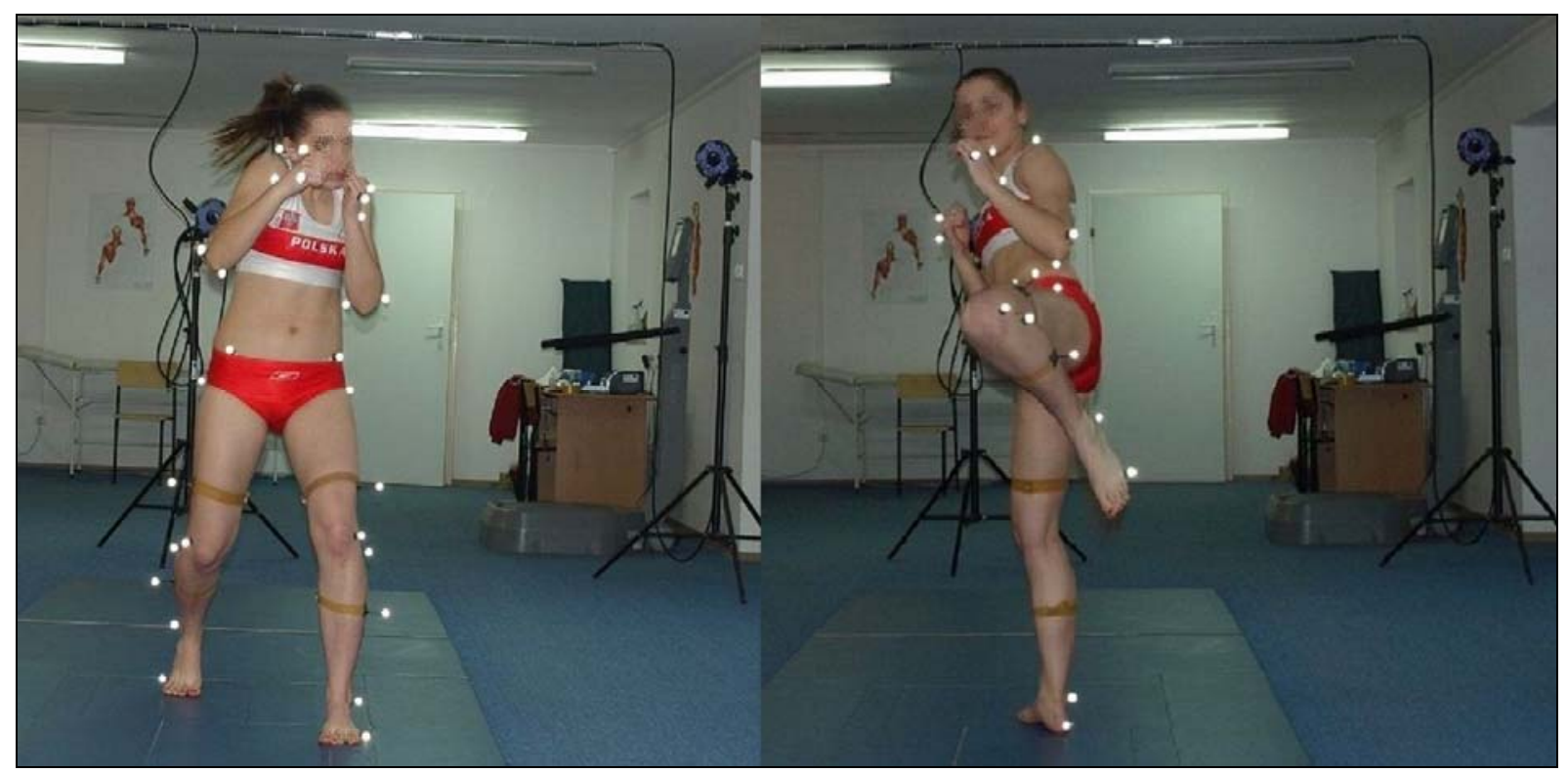

Figure 2. An examples of arrangement of reflective optical markers for BTS Smart system during kick-boxing techniques with example of arrangement 2 of 6 used cameras (photographs were taken in the biomechanics laboratory at University of Rzeszow).

The 3D position of every marker is localized, digitized and then processed by using advanced software. Optical systems allow collecting the information about time and 3D spatial position of each marker placed on human body in millimetre resolution. This data is processed to the spatiotemporal movement variables such as: spatial position, trajectory and range of displacement, velocity, acceleration, rotation of specific body points, joint angles and trajectory of the centre of mass. Commercial software allows also to calculate kinetic parameters such as: momentum, body moment if inertia, kinetic and potential energy. In special software packages, the data is used to create graphs and a stick figure that can be playback as image or animated clip. It allows to quickly compare the measurement results. We can compare e.g. the same variables (such as acceleration, trajectory or joint angles) between various planes of movement or between various points of human body.

The examples of systems used in sport and based on active optical markers are BTS Elite (http://www.btsbioengineering.com) or ODIN (http://www.codamotion.com). The examples of systems based on passive optical markers are APAS - Ariel Performance Analysis System (http://www.arielnet.com), Vicon (http://www.vicon.com), BTS Smart (http://www.btsbioengineering.com), Expert Vision or Mac3D (http://www.motionanalysis.com) and Quintic (http://www.quintic.com). Because the commercial systems often have extremely high prices, much cheaper are systems created by scientists, who work in academic institutions and labs all over the world.

The main advantage of optical systems is their possibility to use unlimited number of markers, high accuracy of motion projections, high spatial and temporal resolution and extremely fast updates. The range of capture speed is between 100 and even $10000 \mathrm{~Hz}$ so that you can 
precisely capture the fast movements. These advantages cause that they are suitable for capture and analysis of fast and dynamic movements, which are typical for combat sport and martial arts.

These systems however, have a lot of drawbacks. The most vital one is extremely high price, and the necessity to use expensive and sophisticated software. The professional movement analysis may be performed only by researchers, who have both knowledge of biomechanics field as well as the ability to process and interpret measurement data. Another disadvantage is the high probability of replacing markers what can distort the input data. Optical markers can be also occluded by props or the performers itself. It can cause that capturing all body parts of the athlete who use the weapon, as well as multiple athletes fight with each other could be difficult. It is also important, when we want to capture movement performed in complex planes, such as turning kicks. In addition, the cameras used in these systems are very sensitive to light and they must be restricted to indoor use, usually under laboratory conditions. Until recently, one more drawback of these systems was complicated calibration process, but in recent years, the solutions that are more user friendly, such as e.g. wand calibration technique in the Vicon system, are applied.

The example problems that could be solved by optical analysis system can be e.g. the detailed knowledge of kinematic parameters of particular point on lower limb of athlete during execution the karate straight kick that last only few second. Such systems allow capturing the movement in natural conditions and with a high accuracy. The real-time monitoring and subsequent analysis of the changes in trajectory of the body centre of mass during the movements of the athlete that performs a specific technique, such as a punch, kick or block may be observed by the coach. It is also possible to track the trajectory and extent of rotation for a specific point e.g. on the fist or a selected segment of the upper limb, at runtime of hook punch in boxing. Thanks to high frequency of optical systems it is possible to capture the movements, about existence which, coaches and athletes are not aware of.

Optical systems are used as a scientific tool for professional biomechanical analysis. The main scientific studies connected with combat sports and martial arts are 3D kinematic analysis of technique and description of movement structure. The example studies analyse such techniques as: karate front kick (Andrzejewski \& Elbaum, 2005), karate jump (Camomilla, Sbriccoli, di Mario, Arpante, \& Felici, 2009), taekwondo straight punch (Wąsik, da Silva Santos, \& Franchini, 2013), taekwondo and yongmudo turning kick (O'Sullivan, et al., 2009) and judo throw (Imamura, Hreljac, Escamilla, \& Edwards, 2006; Imamura, et al., 2007). Other example are studies connected with causes of injuries in taekwondo (Miziara, et al., 2013) or in judo (Koshida, Ishii, Matsuda, \& Hashimoto, 2014).

Electromechanical systems are the next type of human motion capture and analysis solution. This kind of contemporary motion analysis systems are based on exoskeleton or on electrogoniometers (Figure 3). Exoskeleton is the human-shaped constructions that consist a rigid or flexible mechanical parts linked with the sensors (potentiometers or/and goniometers). They are attached to human body joints and they allow monitoring the relative positions between its elements.

In contrast to optical systems electromechanical systems measure directly joint angles. The analysis of the mutual positions between the elements of the exoskeleton allows determining and registering the position of the body in real time. The calculation of kinematic variables is possible when using the professional software.

The advantage of such type of systems is the fact that they can capture motion almost anywhere, are relatively cheap, disruption resistant and wireless. Furthermore, it is a solution which does not require positioning external sensors, no need cameras and has a large range of capture.

The disadvantage of mechanical system is the necessity to use inconvenient exoskeleton, which is uncomfortable to wear for extended time periods and impede motion. The exoskeleton can be restrictive to subject's movement, for instance, a subject cannot roll around on a floor since it will break the device. Additionally, it is the least precise solution that can usually measure angles only in one degree of freedom (DOF), which limits the types of movements that can be captured

Rev. Artes Marciales Asiát., 10(2), 105-123 2015 
(Chen \& Hung, 2010). Because of restrictions on freedom of movement and the limited ability to measure rotational movement in combat sports and martial arts these systems are not used.

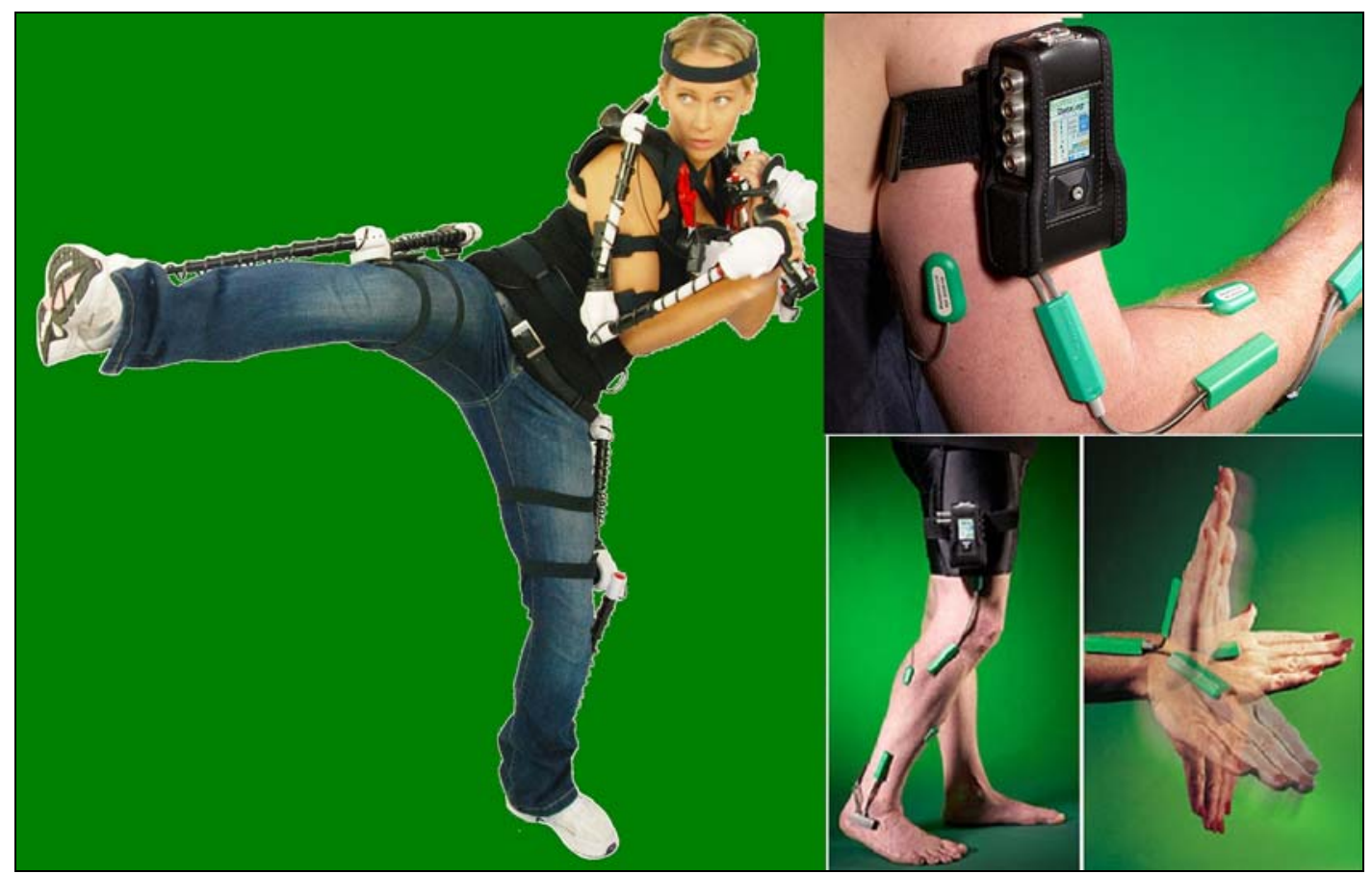

Figure 3. The exoskeleton used in mechanical system Gypsy (retrieved from http://www.animazoo.fr) and the exemplary arrangement of electrogoniometers on upper and lower limb.

Electromagnetic systems are another technical solution used for human motion analysis. These systems are based on the registration of changes in magnetic stream that happen during the change of reciprocal position of the electromagnetic sensors (transmitters and receivers). The subject puts the set of sensors on chosen body part. They are usually linked (to each other and to a computer) with cables. The movement of the body segments is performed in a particular electromagnetic field which allows to identify the position as well as orientation data of each receiver in the 3D space. The required number of sensors for magnetic systems is smaller than the number that is in optical systems, so the number of capture volumes is also smaller.

Variables that can be obtained during the measurement are time, direction, trajectory and range of motion. When using software more kinematic variables (such as velocity and acceleration) can be calculated. The resulting data is typically applied to an inverse kinematics system to create an animated skeleton (Figure 4).

The examples of systems using electromagnetic sensors are Polhemus Motion Tracking System (http://polhemus.com) or Flock of Birds Real Time Motion Tracking System (http://www.ascension-tech.com).

The advantages of electromagnetic systems are that they works better than the others types, in real time and in interactive environments, due to precise identification of sensors. The sensors are never occluded so, it is possible to capture and analyse the movement of multiple athletes interacting simultaneously with multiple setups, like in contact combat sports (judo, wrestling or boxing). Other advantage of these systems are good accuracy and medium update rates (Chen \& Hung, 2010).

The main disadvantage of such systems is the loss or distortion of the signal caused by an interaction with other magnetic fields, the necessity of calibration and a small number of sensors that can be used. Other drawbacks are the small capture area and the range of performed motion limited by cables that linked single sensors. These types of system are usually used under laboratory conditions. 


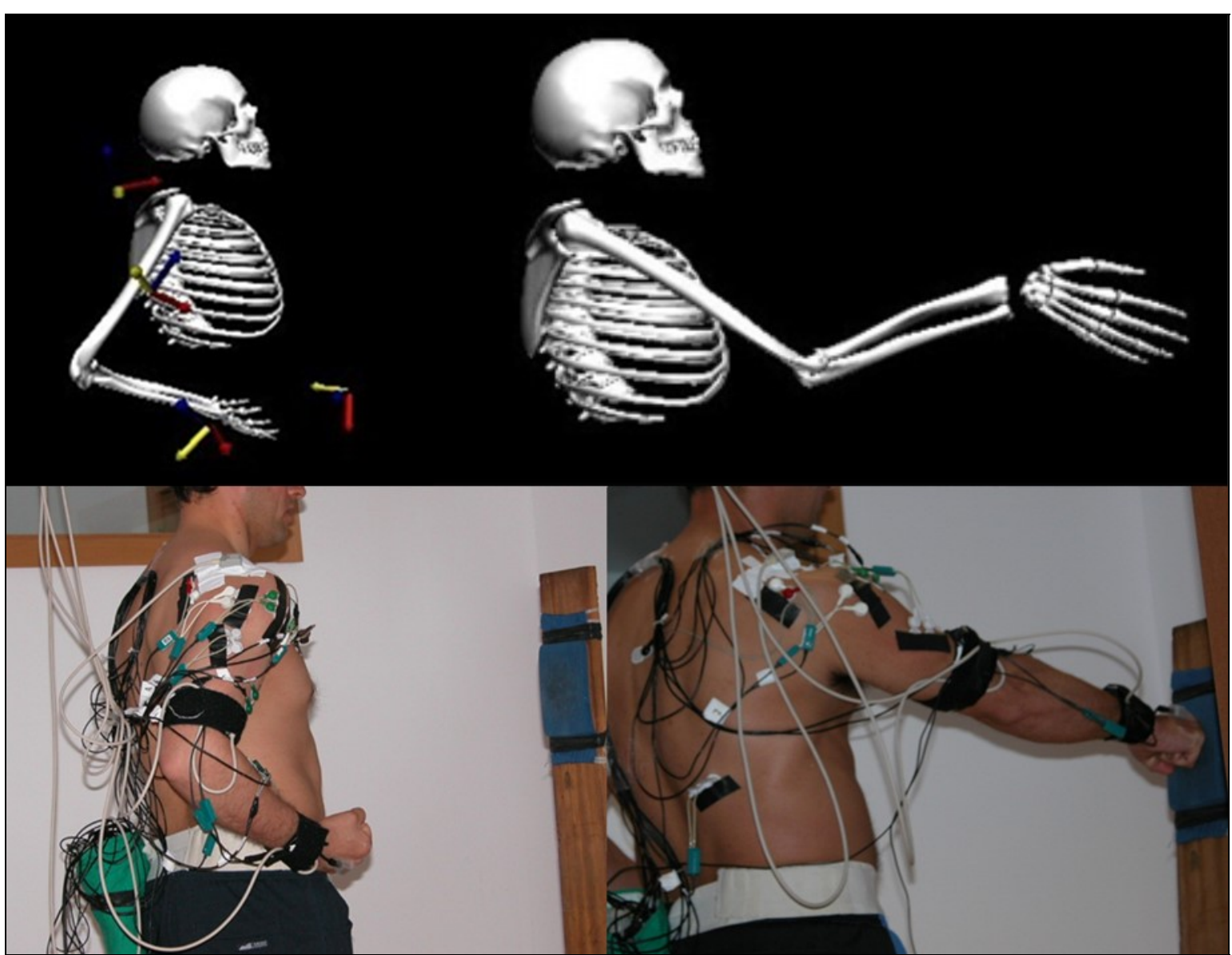

Figure 4. Illustration of a model figure created in real time by the 3D software (Motion Monitor, version 6.05) compatibles to Flock of Birds2 System Ascension Technology (FOB) during the data collecting process of a punch movement in karate (image from VencesBrito research).

Such type of system is used in combat sports and martial arts. An example of research topic are the analysis of karate straight punch (Rodrigues Ferreira \& VencesBrito, 2010; Rodrigues Ferreira \& VencesBrito, 2012; VencesBrito, Rodrigues Ferreira, Cortes, Fernandes, \& PezaratCorreia, 2011). In these studies, scientists used electromagnetic system (Flock of Birds2) for collecting signals, which were used to calculate the kinematic variables for movements of the upper limb. The measurement was performed under laboratory conditions and the calculations were processed using professional software (Figure 4).

Other potential problems that can be solved by electromagnetic systems can be possibility of capture the movement of two athletes, who fight simultaneously, such as in judo or ju-jitsu fight. The fact that such systems do not use the camera, it is possible to obtain detailed kinematic parameters of movement even these athlete's body parts that are obscured.

Acoustic motion analysis systems that use ultrasonic sensors are the next type. In such systems the sensors that are the sources of ultrasonic waves, are placed on particular body parts of the subject. Multiple receivers are placed around the measurement space where the movement is performed. The location of each emitter is based on signals whose duration is proportional to the measured distance.

Modulation of acoustic waves allows retracing the trajectory of motion. Information about the characteristics of gathered waves and their analysis is possible only due to professional software. Such software record spatial positions, velocity, acceleration, body segment angles, and pulse points of each sensor in the real time. The example of such technology is the ZEBRIS system (http://www.zebris.de).

Such systems have many disadvantages: are not portable, can handle only a small number of sensor, the update rate of position and orientation is slow. Additionally, the speed of signals in the 
air depends on the temperature, humidity or barometric pressure in the environment. They are susceptible to interference from environmental noise and echoes, so they are used only under laboratory conditions. In combat sports and martial arts they are not used.

The examples of the new technological solutions are miniature inertial sensors. Such sensors have built-in accelerometers, gyroscope and magnetometers. They allow real time detection of any linear or angular displacement. In order to get a greater freedom of movement all sensors are placed on the subject's body with the use of flexible belts or placed on a special fitting suit (Figure 5). Such suit has 6 degrees of freedom (DOF), the frequency of measurement is $100 \mathrm{~Hz}$ and it allows sending data via Bluetooth wireless connection.

During the measurements, there are obtained the standard variables (as in optical, electromagnetic, and acoustic systems) such as spatial positions and trajectories of individual sensors. Additionally, through the use of accelerometers, it is possible to direct obtain their accelerations and angular velocities. The direct measurement of these variables make it easier to calculate kinetic variables, as the forces and torques. The inertial sensors allow to obtain the motion variables of two athletes fight simultaneously (the data of each athlete's movement individually, even when they interact to each other).

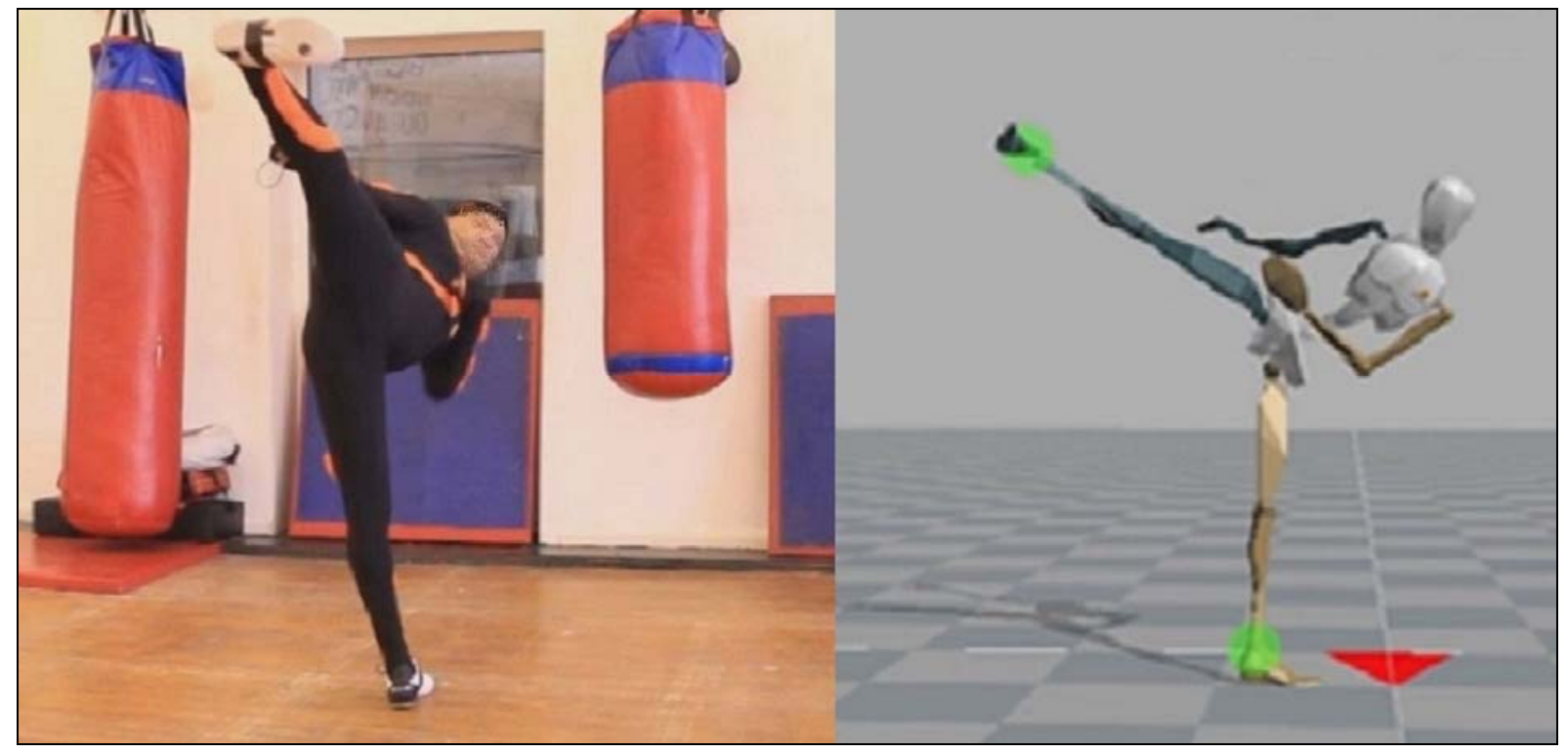

Figure 5. Illustration of Xsens system flexible suit with inertial sensors used for capture taekwondo double side kick and graphic form of captured data (retrieved from https://www.protrain3d.com).

The most crucial advantages of the systems using inertial sensors are that: no need camera, a time of preparation for using is short (no need to stick markers and search for anatomical points) and can be used anywhere (event outdoor and under water). They also make it possible to analyse body movements performed during various contact technique. The disadvantage is the high cost, reducing the possibility of purchase and the need to have specialized knowledge and skills allowing properly process and interpret collected data.

The systems with these solutions used in sports are for example Xsens MVN or MVN Biomech (https://www.xsens.com), Noraxon Myo Motion (http://www.noraxon.com), iSen System (http://www.stt-systems.com), F.A.B. System (http://www.biosynssystems.net). Inertial systems can be used in combat sports and martial arts, but so far there are no scientific publications, presenting the results of such measurements. Potentially, this kind of systems offer the possibility of the fastest and the most precise measurement of acceleration for selected parts of the body that is observed during dynamic punching, kicking, blocking or falling techniques.

The effects of their use in different sports (e.g. rowing, archery, golf, baseball, tennis, swimming and athletics) mobilize many researchers to find interesting application of them also in 
combat sports and martial arts. Such studies are carried out in specialized labs, but their results are not yet widely known. However, it can be seen in other fields, which can become very interesting for both coaches and athletes.

An examples would be interactive mobile 3D applications such, as Protrain Taekwondo or Aikido3d. The first application was specifically designed as a training tool for the World Taekwondo Federation syllabus (http://www.protrain3d.com) and the second to teach the United States Aikido Federation $1^{\text {st }}$ kyu testing requirements (http://www.aikido3d.com).

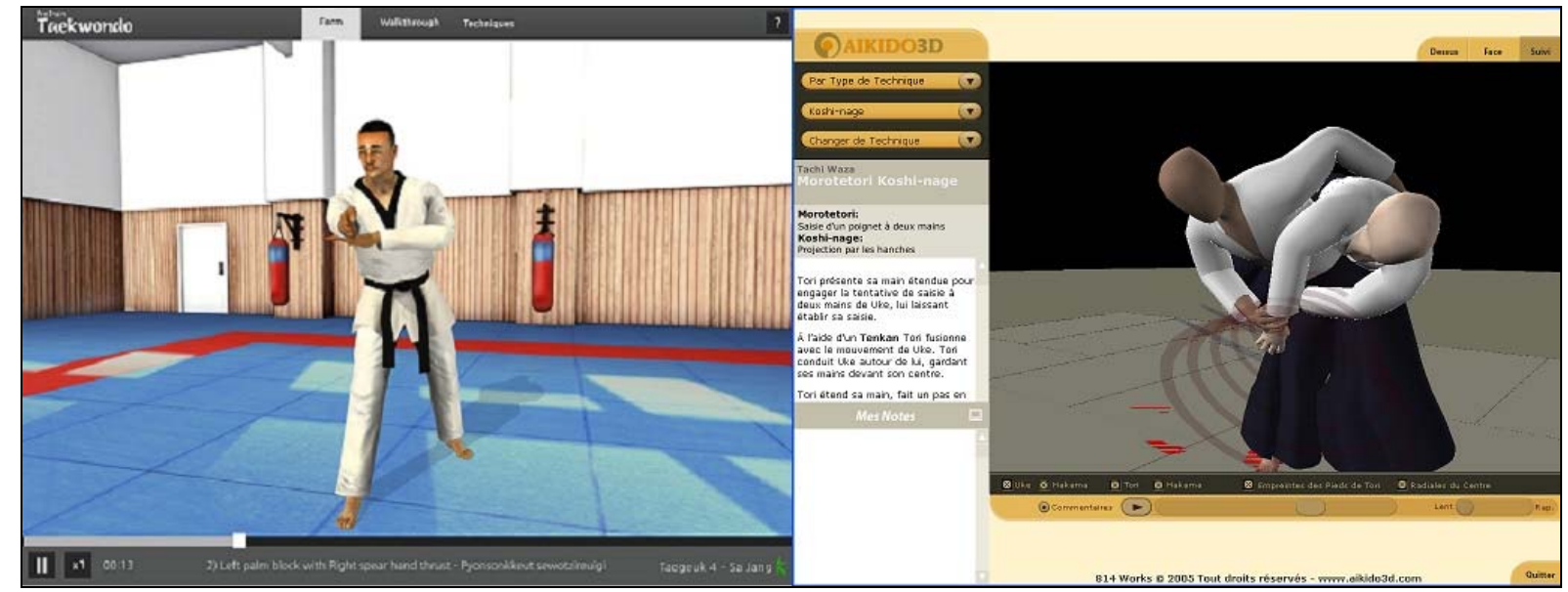

Figure 6. The screenshots of mobile 3D applications Protrain Taekwondo (retrieved from https://www.protrain3d.com) and Aikido3d (retrieved from http://aikido3d.com).

These apps were created as a learning tools that could be taken anywhere out of the training hall. A user can watch the virtual grandmaster, who performs each technique from any angle and at different speeds to see how to do it properly. The audio guide takes him through the special form step by step, and show how to perform each technique correctly and in sequence. Each technique is explained in full, using audio commentary and 3D graphics, so user can learn correct body positioning and weight distribution (Figure 6). It also gives the athlete the capacity to carry visual analysis and a better understanding of technique, which he wants to learn. Although such solution seems not to be fully professional, it can certainly contribute to the promotion of a particular combat sport or martial art. It is clear that this type of training tools cannot substitute the coach, but they may be helpful for amateur athletes.

Modern technology of motion analysis goes in a few new directions. Scientists work on creating technological solutions, which do not require markers on the human body and thus allow observing and analysing the movement performed under natural conditions. What is more important, solutions for motion capturing are becoming cheaper and more available (King \& Paulson, 2007).

The example of the newest technology is Kinect motion sensor. It was introduced in 2010 by Microsoft, mostly for natural interaction in the environment of computer games as a sensor for an Xbox 360 and Xbox One consoles (Khoshelham \& Elberink, 2012). Since 2012 the new variety (at an affordable price) Kinect for Windows is commonly available. Almost immediately, the features of data gathered by Kinect caught the attention of scientists, including those working in motion analysis in sport (Weber, et al., 2012). They have made an attempt to use the Kinect sensors to create a new type of motion analysis systems.

The Kinect contains a RGB camera, depth sensor, infrared light source, three-axis accelerometer and multi-array microphone. The output sensor information can be sent to an external device, such as computer. The rays sent by infrared light source are reflected from the surface of object and people who are in the observed space, and then they are read by the camera in such way that what is closer to the source is brighter and what is further is darker. Kinect sensor is able to track 6 people simultaneously who are located in his field of vision but only two of them can be tracked in wireframe mode. 
Variables that are obtained when using depth sensors can be derived from linear coordinate of the joints which connect the main bones of human body (spatial position, velocity, acceleration) or from bones' Euler angle (Euler angle, angular velocity, angular acceleration, quaternions, rotation matrices). Coordinate system used for linear quantities, can be relative to ground, to the parent joint or to the centre of mass. For angular quantities it can be relative to ground or to the parent joint.

Motion analysis system based on depth sensors and depth-sensing cameras is e.g. iPi Motion Capture (http://ipisoft.com). It consists of equipment (2 Kinect sensors or 3 to 8 Sony PlayStation Eye cameras) and software (iPi Recorder, iPi Mocap Studio, iPi Biomech Add-on). iPi Motion Capture is the tool used to trace 3D movements, to analyse them and to create 3D animation.

The advantage of that kind of motion analysis systems is the possibility to substitute professional cameras with Kinect sensor or with Sony PlayStation cameras which are much cheaper. Another advantage is that the motion trace does not require any markers what is a convenient solution in case of applying in combat sports and martial arts.

The disadvantages are imprecise measurements (low frequency and poor resolution) and restrictions in place of movement (Kopniak, 2012). Microsoft Kinect sensor as well as PlayStation cameras may work successfully only in indoor spaces because they are sensitive to reflection of light. Furthermore, Kinect sensors has a limited width angle of vision and restricted range of measurement space. The range of depth sensor is $0.7-6 \mathrm{~m}$, but the magnitude of the largest correctness is $1.2-3.5 \mathrm{~m}$. 3D image is generated at a frequency of $30 \mathrm{~Hz}$.

The best application for systems based on the depth sensors that allow for performing freely and naturally movements (limited only by specified space) is to use them as an auxiliary tool for teaching the beginners. Their usage allows only for the understanding of the general principles in specific techniques of combat sports or martial arts.
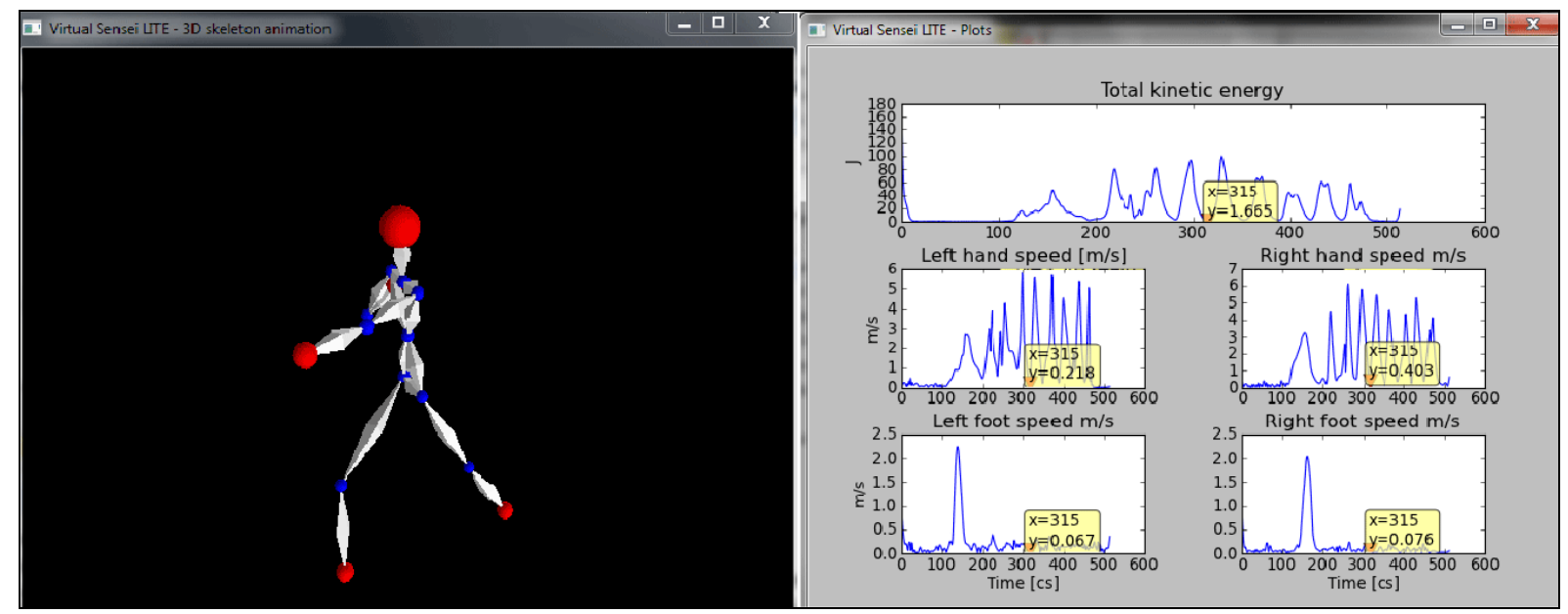

Figure 7. Virtual Sensei Lite screenshots: 3D skeleton animation, with the skeleton reproducing the athlete's motions and the plots of the total kinetic energy of the entire body, expressed in J, and of the hands/feet speeds, in m/s (retrieved from http://www.virtualsensei.it).

The innovative software used to 3D motion analysis in sport and based on Kinect sensor is also Virtual Sensei Lite. This solution is especially dedicated to motion analysis in martial arts, does not require an Xbox video games console and is free of charge (http://www.virtualsensei.it/lite/). The Kinect Virtual Sensei Lite helps users hone their martial prowess by detecting, correcting and demonstrating the proper technique. The software presents a 3D athlete and allows evaluating the levels of kinetic energy released during the action and other kinematic parameters (Figure 7). With Virtual Sensei Lite the athlete can analyse his individual technique, optimize his own execution and improve his performance. It can be also applied for biomechanical analysis. The example results of study conducted with karate athletes are available on software website (http://www.virtualsensei.it/imacsss-conference-presentation/\#more-3030). 
Thus, motion analysis systems that are based on markers, sensors and transmitters can be indirectly used in combat sports and martial arts as a training tool. They provide a data of specific variables that are usually used for the quantitative analysis of the movement. Most of them can be combined and synchronised with other measuring apparatus e.g. the force platform (isometric or stabilographic) and / or EMG. They can also be applied with video camcorders or reference camera. To analyse such data, both a professional knowledge of physiology and biomechanics, as well as the ability to interpret measurement results is needed. In addition, some systems can be used only under laboratory conditions, because their hardware has special requirements. Therefore, coaches and athletes can benefit from such systems indirectly when they cooperate with researchers. Coaches and athletes can also use the modern technical solutions, which thanks to using motion analysis systems are based on animation and virtual reality. Such solutions that are dedicated for some combat sports are now available.

Summarize, if the coaches or athletes are interested of kinematic variables of precise body point that can be useful in better understanding the correctness of performance, identifying errors or determining the causes of injuries they should use the systems based on markers, sensors or transmitters. But they must to consider the precision of output data and requirements of measurement environment. Optical systems are the most precise for obtaining values of positioning and trajectory of particular body points but they need to be used under laboratory condition. Electromagnetic systems allow obtaining precise values using less number of sensors and they also need to be used under laboratory conditions. Inertial systems are the best for precise measurement of velocity and angular acceleration and can be use in each environment. Additionally, such systems allow capturing the movement during the immediate fight of two athletes. Depth-sensing systems are the cheapest solution but they are not precise and they can be also used under special conditions.

As in the case of video-based systems, those systems also can be used for visual feedback. They allow observing on computer screen the athlete's body as animated figure (e.g. in stick mode or wireframe mode). Such images can be repeatedly view from different perspectives, with various speeds and with possibility of using freeze frames at any time.

Systems based on markers, sensors or transmitters allow for observing registered motion in real time and for calculating obtained variables using special software packages. Such systems allow obtaining precise values of kinematic variables such as position, trajectory, velocity and acceleration of specific body point, centre of mass trajectory, joint angles, angular velocity and acceleration. The quantitative analysis of these variables allow for monitoring the correctness of the individual technique performed by the same athlete at predetermined time intervals (e.g. once a month) and identifying errors in execution (including those that may cause injuries). Many software allow to obtain kinetic variables (such as forces, momentum, torques, kinetic and potential energy generated by particular parts of the athlete's body during the implementation of specific technique) but the values of calculated variables can be imprecise. Much better solutions for obtaining precise values of kinetic variables is using the special dynamometers or force platforms.

\section{Conclusions}

The aim of this study was to present the diversity of motion analysis systems that can be applied in combat sports and martial arts. The indication of example applications in scientific research and range of applications in optimizing the training process, taking into account the main advantages and disadvantages of using them, allows to formulate the following conclusion.

The contemporary motion analysis systems allow to obtain the detailed information that can be used for qualitative or quantitative analysis of movement performed by the athlete. The proper utilizing such information by the coaches and athletes allows them to correct or eliminate errors, as well as reduce the causes of injury, what may have an impact on improving the efficiency and effectiveness of training process.

Not all types of motion analysis systems used in sport are suitable for combat sports and martial arts. Scientific studies conducted so far showed the usefulness of video-based, optical and 
electromechanical systems. There are also ongoing researches into the use of inertial systems. Use the results of scientific studies by coaches and athletes can allow them to improve techniques and tactics, as well as prevent injuries and ultimately optimize the training effects.

Coaches and athletes can use motion analysis systems as a useful training tool either directly or indirectly. Directly, they can use video analysis systems based on the widely available video camcorders and more user friendly and available free of charge software. They can also analyse the motion using modern software and mobile applications that are dedicated for combat sports or martial arts. In order to perform professional analyses, they should use the support of scientists. Indirectly, they can use commercial analysis systems, based on markers, sensors or transmitters. But professional analysis registered by such types of systems need the physiological and biomechanical knowledge. So if coaches or athletes want to benefit the commercial analysis systems they should to cooperate with scientists.

\section{References}

Aggarwal, J. K., \& Cai, Q. (1999). Human motion analysis: a review. Computer Vision and Image Understanding, 73(3), 428-440. http://doi.org/10.1006/cviu.1998.0744

Andrzejewski, X., \& Elbaum, L. (2005). Biomechanical analvsis of the front kick with the dominant and non-dominant limb in the Shito-Ryu style of karate. In ISBS-Conference Proceedings ( $\mathrm{p}$. 843). Beijing, China.

Balsalobre-Fernández, C., Martinez-Majolero, V., Villacieros-Rodriguez, J., \& Tejero-González, C. M. (2013). Diferencias en el salto vertical y la velocidad de patada mae-geri entre karatekas internacionales y nacionales. Revista de Artes Marciales Asiáticas, 8(1), 13-20.

Barris, S., \& Button, C. (2008). A review of vision-based motion analysis in sport. Sports Medicine (Auckland, N.Z.), 38(12), 1025-1043. http://doi.org/10.2165/00007256-200838120-00006

Camomilla, V., Sbriccoli, P., di Mario, A., Arpante, A., \& Felici, F. (2009). Comparison of two variants of a Kata technique (Unsu): The neuromechanical point of view. Journal of Sports Science and Medicine, 8(CSSI-3), 29-35.

Chen, Y. J., \& Hung, Y. C. (2010). Using real-time acceleration data for exercise movement training with a decision tree approach. Expert Systems with Applications, 37(12), 7552-7556. http://doi.org/10.1016/j.eswa.2010.04.089

Del Vecchio, F. B., Silva, J. J. R., \& Farias, C. B. (2015). Análise temporal de combates de Muay-Thai de nível nacional: Efeitos da fase competitiva. Revista de Artes Marciales Asiáticas, 10(1), 34-41. http://doi.org/10.18002/rama.v10i1.1635

Drużbicki, M., Szymczyk, D., Snela, S., Dudek, J., \& Chuchla, M. (2009). Obiektywne, ilościowe metody analizy chodu w praktyce klinicznej [Objective, quantitative methods of gait analysis in clinical practice]. Przegląd Medyczny Uniwersytetu Rzeszowskiego, VII(4), 356-362.

Erdmann, W. S. (2003). Metody obrazowe badania techniki ruchu w sporcie [Visual methods for testing movenet techniques in sport]. In C. Urbanik (Ed.), Zagadnienia biomechaniki sportu technika sportowa [The issues biomechanics of sport - sports technique] (pp. 19-40). Warszawa: Akademia Wychowania Fizycznego Józefa Piłsudskiego.

Falco, C., Landeo, R., Menescardi, C., Bermejo, J. L., \& Estevan, I. (2012). Match Analysis in a University Taekwondo Championship. Advances in Physical Education, 2(1), 28-31. http://doi.org/10.4236/ape.2012.21005

Ferreira Santos, V. G., de Oliviera Pires, F., Bertuzzi, R., Franchini, E., da Silva-Cavalcante, M., Peduti Dal Molin Kiss, M. A., \& Lima-Silva, A. E. (2014). Relationship between attack and pause in world taekwondo championship contests: effects of gender and weight category. Muscles, Ligaments and Tendons Journal, 4(2), 127-131. http://doi.org/10.11138/mltj/2014.4.2.127

Gavrila, D. M. (1999). The Visual analysis of human movement: a survey. Computer Vision and Image Understanding, 73(1), 82-98. http://doi.org/10.1006/cviu.1998.0716

Gianino, C. (2010). Physics of Karate. Kinematics analysis of karate techniques by a digital movie camera. Latin-American Journal of Physics Education, 4(1), 32-34.

Grimshaw, P., Lees, A., Fowlers, N., \& Burden, A. (2010). Biomechanika Sportu. Krótkie wykłady [Sports \& Exercise Biomechanics. Instant Notes]. Warszawa: Wydawnictwo Naukowe PWN. 
Harun, H., \& Xiong, S. J. (2010). The symmetry in kinematics between the dominant and nondominant legs in taekwondo turning kick. Retrieved from http://eprints.utm.my/10720/1/The_Symmetry_In_Kinematics_Between_The_Dominant_An d_Non.pdf

Hassmann, M., Buchegger, M., \& Stollberg, K.-P. (2011). Judo performance tests using a pulling force device simulating a Seoi-Nage throw. IDO Movement for Culture. Journal of Martial Arts Anthropology, 11(3), 47-51.

Imamura, R. T., Hreljac, A., Escamilla, R. F., \& Edwards, W. B. (2006). A three-dimensional analysis of the center of mass for three different judo throwing techniques. Journal of Sports Science and Medicine, 5(CSSI-1), 122-131.

Imamura, R. T., Iteya, M., Hreljac, A., \& Escamilla, R. F. (2007). A kinematic comparison of the judo throw harai-goshi during competitive and non-competitive conditions. Journal of Sports Science and Medicine, 6(CSSI-2), 15-22.

Jabłoński, B., Klempous, R., \& Majchrzak, D. (2005). Analiza możliwości identyfikacji ruchu postaci w oparciu o technikę Motion Capture [Analysis of the possibility of motion identifying based on Motion Capture technology]. In M. Ganzha, M. Paprzycki, J. Wachowicz, \& K. Węcel (Eds.), XXI Autumn Meeting of Polish Information Processing Society Conference Proceedings (pp. 121129). Wisła.

Kalichová, M., Vít, M., Reguli, Z., \& Pieter, W. (2012). Kinematic characterization of the Capoeira Bencao Kick. IDO Movement for Culture. Journal of Martial Arts Anthropology Movement for Culture, 12(4), 7-11.

Kautzner, N., \& Junior, M. (2012). Effort during the Shotokan Karate Kumite in 13th Brazilian Championship JKA, 2012. Revista Digital. Buenos Aires, 17(172). Retrieved from http://www.efdeportes.com/efd172/effort-during-the-shotokan-karate-kumite.htm

Khoshelham, K., \& Elberink, S. O. (2012). Accuracy and resolution of kinect depth data for indoor mapping applications. Sensors, 12(2), 1437-1454. http://doi.org/10.3390/s120201437

King, B. A., \& Paulson, L. D. (2007). Motion capture moves into new realms. Computer, 40(9), 13-16.

Kochhar, T., Back, D. L., Mann, B., \& Skinner, J. (2005). Risk of cervical injuries in mixed martial arts. British Journal of Sports Medicine, 39(7), 444-447. http://doi.org/10.1136/bjsm.2004.011270

Kopniak, P. (2012). Rejestracja ruchu za pomocą urzą dzenia Microsoft Kinect [Motion capture with Microsoft Kinect sensor]. Pomiary, Automatyka, Kontrola, 58(11), 1016-1018.

Koshida, S., Ishii, T., Matsuda, T., \& Hashimoto, T. (2014). Biomechanics of judo backward breakfall: comparison between experienced and novice judokas. Archives of Budo, 10, 187-194.

Król, H., \& Mynarski, W. (2005). Cechy ruchu - charakterystyka i moźliwości parametryzacji [Features of movement - characteristics and capabilities of parametryzation]. Katowice: Akademia Wychowania Fizycznego.

Liebermann, D. G., Katz, L., Hughes, M. D., Bartlett, R. M., McClements, J., \& Franks, I. M. (2002). Advances in the application of information technology to sport performance. Journal of Sports Sciences, 20(10), 755-769. http://doi.org/10.1080/026404102320675611

Magalhaes, F. A., Sawacha, Z., Di Michele, R., Cortesi, M., Gatta, G., \& Fantozzi, S. (2013). Effectiveness of an automatic tracking software in underwater motion analysis. Journal of Sports Science and Medicine, 12(4), 660-667.

Miarka, B., Hayashida, C. R., Julio, U. F., Calmet, M., \& Franchini, E. (2011). Objectivity of FRAMIsoftware for judo match analysis. International Journal of Performance Analysis in Sport, 11, 254-266.

Miziara, I. M., Pereira, A. A., Martins Naves, E. L., Andrade, A. O., Soares dos Santos, S., Furtado, D. A., \& Naves Júnior, J. D. (2013). Corelation between muscle activity and taekwondo movements: a proposal of study. In XXIV Congress of the International Society of Biomechanics; XV Brazilian Congress of Biomechanics.

Moeslund, T. B., \& Granum, E. (2001). A survey of computer vision-based human motion capture. Computer Vision and Image Understanding, 81(3), 231-268. http://doi.org/10.1006/cviu.2000.0897

Moeslund, T. B., Hilton, A., \& Krüger, V. (2006). A survey of advances in vision-based human motion capture and analysis. Computer Vision and Image Understanding, 104(2-3 SPEC. ISS.), 90-126. http://doi.org/10.1016/j.cviu.2006.08.002 
O’Sullivan, D., Chung, C., Lee, K., Kim, E., Kang, S., Kim, T., \& Shin, I. (2009). Measurement and comparison of Taekwondo and Yongmudo turning kick impact force for two target heights. Journal of Sports Science and Medicine, 8(CSSI-3), 13-16.

Roberts, S., Trewartha, G., \& Stokes, K. (2006). A comparison of time-motion analysis methods for field based sports. International Journal of Sports Physiology and Performance, 1(4), 388-399.

Rodrigues Ferreira, M. A., \& VencesBrito, A. M. (2010). Electromechanical delay in ballistic movement of superior limb: comparison between karate athletes and nonathletes. Perceptual and Motor Skills, 111(3), 722-734. http://doi.org/10.2466/05.25.PMS.111.6.722-734

Rodrigues Ferreira, M. A., \& VencesBrito, A. M. (2012). Sex differences in electromechanical delay during a punch movement. Perceptual and Motor Skills, 115(1), 228-240. http://doi.org/10.2466/25.06.26.PMS.115.4.228-240

Silva, J. J. R., Del Vecchio, F. B., Picanço, L. M., Takito, M. Y., \& Franchini, E. (2011). Time-motion analysis in Muay-Thai and Kick-Boxing amateur matches. Journal of Human Sport and Exercise, 6(3), 490-496. http://doi.org/10.4100/jhse.2011.63.02

Van der Zijden, A. M., Groen, B. E., Tanck, E., Nienhuis, B., Verdonschot, N., \& Weerdesteyn, V. (2012). Can martial arts techniques reduce fall severity? An in vivo study of femoral loading configurations in sideways falls. Journal of Biomechanics, 45(9), 1650-1655. http://doi.org/10.1016/j.jbiomech.2012.03.024

VencesBrito, A. M. (2012). Caracterização cinesiológica do choku-tsuki executado com impacto e sua comparação com a execução sem impacto. Revista de Artes Marciales Asiáticas, 7(1), 1225.

VencesBrito, A. M., Colaço Branco, M. A., Cordeiro Fernandes, R. M., Rodrigues Ferreira, M. A., Fernandes, O. J. S. M., Figueiredo, A. A., \& Cynarski, W. J. (2014). Avaliação eletromiográfica e cinemática do pontapé Mae-geri em karatecas de elite competitiva e karatecas cinto negro não competidores. Revista Da UIIPS, 2(3), 84-103.

VencesBrito, A. M., Rodrigues Ferreira, M. A., Cortes, N., Fernandes, O., \& Pezarat-Correia, P. (2011). Kinematic and electromyographic analyses of a karate punch. Journal of Electromyography and Kinesiology, 21(6), 1023-1029. http://doi.org/10.1016/j.jelekin.2011.09.007

Wang, L., Hu, W., \& Tan, T. (2003). Recent developments in human motion analysis. Pattern Recognition, 36(3), 585-601. http://doi.org/10.1016/S0031-3203(02)00100-0

Wąsik, J., da Silva Santos, J. F., \& Franchini, E. (2013). Movement structure and kinetics of the traditional straight punch: measurements in taekwon-do athletes. IDO Movement for Culture. Journal of Martial Arts Anthropology, 13(1), 42-47. http://doi.org/10.14589/ido.13.1.6

Weber, I., Koch, J., Meskemper, J., Friedl, K., Heinrich, K., \& Hartmann, U. (2012). Is the MS Kinect suitable for motion analysis? Biomedical Engineering. Biomedizinische Technik, 57(SI-1), 664. http://doi.org/10.1515/bmt-2012-4452

Wilson, B. D. (2008). Development in video technology for coaching. Sports Technology, 1(1), 34-40. http://doi.org/10.1002/jst.9

Zvonar, M., Kolarova, K., Zahradnicek, V., Reguli, Z., \& Vít, M. (2012). Kinematic Analysis in Combative Sports. IDO Movement for Culture. Journal of Martial Arts Anthropology, 12(4), 1219.

\section{Internet sources}

http://biometricsltd.com

http://ipisoft.com

http://polhemus.com

http://video4coach.com

http://www.animazoo.fr

http://www.ascension-tech.com

http://www.aikido3d.com

http://www.arielnet.com

http://www.biosynssystems.net

http://www.btsbioengineering.com

http://www.codamotion.com

http://www.dartfish.com

http://www.kinovea.org 
http://www.motionanalysis.com

http://www.noraxon.com

http://www.protrain3d.com

http://www.quintic.com

http://www.siliconcoach.co

http://www.simi.com

http://www.stt-systems.com

http://www.vicon.com

http://www.virtualsensei.it/lite

http://www.xsens.com

http://www.zebris.de

\section{Author's biographical data}

EwaPolak (PhD), MSc and PhD in Sport Science, coach in Trampoline Gymnastics. Senior lecturer at the University of Rzeszow (Poland). She is the head of the Unit of Individual Sports at the Faculty of Physical Education. Author and co-author in Polish monographs and national journals in Sport Science fields, generally in history of gymnastic sports and issues of kinesiology in sport of children and adolescents. In the recent years, she is interested in possibilities of using the modern IT in sport training process. She has participated in more over 20 scientific national and international conferences, among others in $3^{\text {rd }}$ World Scientific Congress of Combat Sports and Martial Arts (2014). E-mail: ewpol@op.pl

Jerzy Kulasa (MSc), MSc of Physics. He is a lecturer at the Faculty of Physical Education - the University of Rzeszow (Poland). The main fields of his scientific research are: computer science, IT in sport, biomechanics, martial arts and combat sports. He was a member of organizing committee and an active participant in three World Scientific Congresses of Combat Sports and Martial Arts in Rzeszow (2014, 2010, \& 2006). In doctoral thesis he works on the computer recording of the judo struggle and analysis of its dynamic. E-mail: jkulasa@wp.pl

AntónioM. V. VencesBrito, PhD in Human Kinetics in the speciality of Motricity Sciences and with the Specialist degree in Formation of Karate Coaches, MSc in High Performance Training and BSc in Radiology and in Sport Sciences. Senior lecturer in Anatomophysiology and Sports Modality - Karate in the Sports Sciences School of Rio Maior, Polytechnic Institute of Santarém, Portugal. Shotokan karate practitioner since 1975 and collaborator of the Portuguese Karate Federation. Researcher of the Investigation Centre in Life Quality (CIEQV), member of the European College of Sport Sciences and of the International Martial Arts and Combat Sports Scientific Society (IMACSSS). Research focuses on kinesiology, neural control and coordination of the muscles activity, sport physiology and in sport injuries. Has been publishing and is reviewer in national and international scientific journals and conferences. E-mail: abrito@esdrm.ipsantarem.pt

Maria António Castro (PhD), Pos-Doc in Motor Behaviour and PhD in Physiotherapy. Senior lecturer at Coimbra Health School, Instituto Politécnico de Coimbra, Portugal (Human Movement, Biomechanics, Sport Physiotherapy, Manual Therapy). Chairman of the Physiotherapy Scientific board and of the research Laboratory Robocorp. Researcher at the Mechanical Engineering Research Centre - University of Coimbra. Research interests in movement analysis, biomechanics and motor control of human movements, sports injuries, injury prevention and health promotion. Has been publishing in national and international journals and is a reviewer for scientific journals and conferences. E-mail: mac@estescoimbra.pt

Orlando J. Fernandes (PhD), is Master and PhD, in Sports Science. Currently is assistant Professor in Évora University, teaching Analyses of Human Movement and Biomechanics in Sports Science and Physical Therapy. His research focus on biomechanical analysis of human movement specifically related to injury prevention and nonlinear methods applied to human movement. Member of the Interdisciplinary Centre for the Study of Human Performance (CIPER), the Research Unit of the Faculdade de Motricidade Humana da Universidade de Lisboa. Research topics: sports and physical therapy, biomechanics, motor control, neuromuscular function, movement variability and data processing. E-mail: orlandoj@uevora.pt 